\title{
The Assessment of Plasma Fatty Acid Profiles in Newly Diagnosed Treatment-Naïve Paediatric Crohn's Disease
}

\section{Jan SCHWARZ ${ }^{1}$, Marek VECKA ${ }^{2}$, František STOŽICKÝ ${ }^{1}$, Renáta POMAHAČOVÁ ${ }^{1}$, Barbora STAŇKOVÁ ${ }^{2}$, Eva TVRZICKÁ ${ }^{2}$, Marcela KRESLOVÁ ${ }^{1}$, Romana ZAHÁLKOVÁ Josef SÝKORA ${ }^{1}$}

${ }^{1}$ Charles University in Prague, Faculty of Medicine in Pilsen, Faculty Hospital, Department of Paediatrics, Pilsen, Czech Republic, ${ }^{2}$ Fourth Department of Medicine, First Faculty of Medicine, Charles University, General University Hospital and Institute of Clinical Chemistry and Laboratory Diagnostics, Prague, Czech Republic

Received February 19, 2021

Accepted July 27, 2021

Epub Ahead of Print September 10, 2021

\section{Summary}

Fatty acid (FA) profiles as potentially relevant components of Crohn's disease (CD) have been insufficiently analysed. We sought to explore the plasma profiles of $n-3$ and $n-6$ polyunsaturated fatty acids (PUFAs) in newly diagnosed untreated active CD. We included 26 consecutive $C D$ pediatric patients (<19 years) and 14 healthy controls (HCs). Disease characteristics, including inflammatory markers, dietary histories, and the Pediatric Crohn's Disease Activity Index (PCDAI), were obtained. The profiles of plasma FAs in plasma lipid classes were analysed by gas chromatography with FID detection of methyl esters. The erythrocyte sedimentation rate, C-reactive protein level and fecal calprotectin level (all $p<0.001$ ) were significantly higher in $C D$ patients than in HCs. Most changes were observed in plasma phospholipids (PLs), such as a higher content of $n-3$ and changes in $n-6$ long-chain PUFAs in the CD group. The CD group had a lower ratio of $n-6 / n-3$ PUFAs in PLs $(p<0.001)$ and triacylglycerols (TAGs) $(p<0.01)$. Correlations of the FA content in plasma PLs with disease activity scores of $C D$ were also observed, which were positive for the sum of monounsaturated fatty acids (MUFAs) as well as oleic acid $(18: 1 n-9)$ (both $p<0.05$ ). The metabolism of PUFAs is significantly altered even in treatment-naive newly diagnosed active pediatric $C D$, and the content of major FAs in PLs correlates with disease activity and inflammatory markers, thus probably contributing to the still unclear early disease pathogenesis.

\section{Key words}

Children • Crohn's disease • Inflammation • Polyunsaturated fatty acids • Profiling

\section{Corresponding author}

J. Schwarz, Division of Pediatric Gastroenterology, Department of Pediatrics, Faculty Hospital, Faculty of Medicine in Pilsen, Charles University in Prague, Alej Svobody 80, 304 00, Pilsen, Czech Republic; Fax: +420 377104694. E-mail: schwarzj@fnplzen.cz

\section{Introduction}

The etiology of inflammatory bowel disease (IBD) including Crohn's disease (CD) and ulcerative colitis (UC) remains unresolved, and approximately $25 \%$ of patients with IBD present before the age 20 years (Sýkora et al. 2018).

Dietary essential fatty acids (EFAs), linoleic acid (LA, 18:2n-6) and alpha-linolenic acid (ALA, 18:3n-3), the principal sources of omega $3(n-3)$ and omega $6(n-6)$ 18-carbon (18C) polyunsaturated FAs (PUFAs), can be converted to biologically active long-chain (LC>20) PUFAs (Chilton et al. 2017). LC PUFAs, their metabolites and gut environmental factors profoundly influence the immune response, and mediators of FAs may have different effects on intestinal inflammation (Saika et al. 2019, Nagatake et al. 2019). n-6 LC PUFAs (e.g. arachidonic acid [ARA], 20:4n-6) promote 
pro-inflammatory effects. Eicosapentaenoic acid (EPA, 20:5n-3) and docosahexaenoic acid (DHA, 22:6n-3), representing n-3 PUFAs, exert anti-inflammatory properties (Serhan et al. 2014). n-6 FAs may inhibit the inflammation-resolving effect of n-3 derivatives (Harris et al. 2017, Gonzales-Gil et al. 2016, Innes et al. 2018); however, the interactions are understudied. High intakes of animal fat and n-6 LC PUFA intake were linked to higher CD prevalence (Costea et al. 2014, Hou et al. 2011), and higher dietary n-3 LC PUFA intake could alleviate the risk of CD (Scoville et al. 2019). Many studies have been conducted to understand the influence of dietary intervention in IBD (Lewis et al. 2017, Nielsen et al. 2005, Faegan et al. 2008, Marion-Letellier et al. 2013), yet the filed remains a controversial one. These studies, however, did not take into account many interacting factors, including drugs, diet or measurable FAs. Although several studies have suggested that alterations in plasma FAs might be crucial to unravelling the underlying pathology of CD (Marton et al. 2019, Costea et al. 2014), there has been no pediatric study to evaluate the profile of FAs in newly diagnosed untreated CD.

Therefore, we decided to evaluate the FA profile in the main plasma lipid classes in newly diagnosed treatment-naïve CD children. The specific aims were as follows: (1) to compare the results of those with $\mathrm{CD}$ with those of healthy controls (HCs) and (2) to assess possible correlations with disease activity.

\section{Methods}

\section{Study population and design}

\section{Flow chart of the participants and exclusion criteria}

We performed a prospective study, consecutively enrolling all new-onset untreated $\mathrm{CD}$ patients. A total of 44 pediatric $C D$ patients under the age of 19 years visiting our tertiary referral center were screened for eligibility in this trial. After CD diagnosis had been established and eligibility criteria had been met, $26 \mathrm{CD}$ patients with newly diagnosed CD were enrolled. HCs were recruited in the same period according to the following criteria: routine health check-ups, minor elective surgery or regularly scheduled visits for non-CDrelated complaints. None of these HCs had any active inflammation, a history of chronic disease or previous intestinal resection capable of influencing absorption, or any signs or family history of $\mathrm{CD}$. The participants included in the study were from the same place of residence with similar demographic variables. The criteria for exclusion were as follows: (1) concomitant organic/metabolic disease, (2) history of bowel surgery, (3) previous diagnosis of IBD, (4) abnormal liver or renal function, (5) severe colitis requiring intensive medical management, and (6) the presence of a serious comorbidity. None of the study participants were taking any drugs, CD-specific therapy or regular consumption of PUFAs at the time of sampling. Basic information was recorded. Prospective data were drawn from a departmental in-house computerized standardized interactive database as reported in our recent study (Sýkora et al. 2018).

\section{Nutritional variables}

We used prospective 3-day dietary records with the help of an experienced nutritionist to gather reasonable data on the children's dietary pattern. All data were subsequently entered and analysed using nutritional interactive computer software (Nutripro Software, Czech Republic, http://Nutripro.cz), and the intakes were then downloaded for subsequent analyses. We calculated the intake of energy, total fat, SFAs, MUFAs, and PUFAs (n-3 and n-6 FAs) for each subject to examine changes in the studied groups, including the proportions of total energy intake (g, \% kcal, g/1000 kcal).

\section{Diagnosis, disease classification and disease activity}

All CD diagnoses fulfilled the revised Porto criteria (Levine et al. 2014) and the Paris classification, including age at diagnosis (A), disease location (L), disease behavior (B) and growth delay (G) (Levine et al. 2011). The Pediatric Crohn's Disease Activity Index (PCDAI) characterizes disease activity (Hyams et al. 2005). A score of 0 to 10 corresponds to no disease activity; mild disease equals a score of 11 to 30 , and a score of 31 or greater represents moderate to severe disease activity.

\section{Markers related to inflammation or disease activity}

The erythrocyte sedimentation rate (ESR) and C-reactive protein (CRP) were measured by routine laboratory assays. Fecal calprotectin (FC) was assayed before bowel preparation using a quantitative enzyme immunoassay (PhiCal test, Calpro AS).

Analysis of plasma FAs using gas chromatography The profile of plasma FAs in plasma lipid classes 
was analysed by gas chromatography (Vecka et al. 2002). All pediatric subjects were required to fast overnight for a minimum of $12 \mathrm{~h}$ prior to blood collection and separation of plasma. Briefly, the plasma was extracted according to a study by Folch et al. (1957), and the lipid classes were isolated by TLC, transesterified with sodium methanolate and analysed by gas chromatography with a platform consisting of GC-FOCUS with an AI 1310 automatic sampler (Thermo Fisher Scientific SpA., Milan, Italy). A fused silica capillary column $(30 \mathrm{~m} \times 0.32 \mathrm{~mm}$ ID) with chemically bonded stationary phase DB-WAXETR from J\&W Scientific (Folsom) was used. The oven temperature was maintained for $1 \mathrm{~min}$ at $80^{\circ} \mathrm{C}$, raised to $150{ }^{\circ} \mathrm{C}$ by $20 \mathrm{~K} / \mathrm{min}$, then raised to $250^{\circ} \mathrm{C}$ by $3 \mathrm{~K} / \mathrm{min}$ and kept for $5 \mathrm{~min}$; hydrogen was used as the carrier gas. The injector and detector temperatures were set at $250{ }^{\circ} \mathrm{C}$. Individual peaks of FA methyl esters were identified by comparing the retention times with those of authentic standards (Nu-Chek Prep, Elysian, MN, U.S.A.).

\section{Statistical analyses}

STATISTICA CZ ver. 12 (StatSoft Inc., Tulsa, USA) software was used for statistical processing of the results. A descriptive statistical analysis was performed for baseline characteristics. Non-normally distributed variables were log-transformed. For the data analysis, significant differences between groups were assessed by the MannWhitney $U$-test for non-transformed variables or by the $t$-test for transformed variables. Distribution differences were calculated using the chi-square test with Yates's correction where appropriate. Correlations were evaluated with the Spearman rank test. The p-value was adjusted for multiple comparisons using Benjamini-Hochberg correction.

\section{Ethical issues}

The present study was conducted according to Good Clinical Practice and the Declaration of Helsinki. The research was approved by the institution's ethics review board. Written informed consent was obtained from the parents/legal guardians before participation in the study.

\section{Results}

\section{Demographics of the study population}

The baseline characteristics of the two groups, including inflammatory markers, are shown in Table 1, whereas full details of the constructs of the Paris classification and disease activity according to the PCDAI are given in Table 2. All children were predominantly of Czech ethnicity (Caucasian). A total of 42 subjects, $26 \mathrm{CD}$ patients and $16 \mathrm{HCs}$, were enrolled in this study. There were no significant differences between the 2 studied groups except for the highly increased values of inflammatory markers in the $\mathrm{CD}$ patients (all $\mathrm{p}<0.001$ ).

\section{Dietary assessment}

The subjects' mean daily nutrient intake is summarized in Table 3. The median time between sampling and completion of all dietary assessments was 4.5 (range 1-12) days. No significant differences were observed in the total energy intake, total fat and FA composition of the dietary intake in the $\mathrm{CD}$ patients (SA, MUFA, PUFA, n-3 FA and n-6 FA) when compared with levels in HCs ( $>00.05)$. Energy from fat in children's diets did not exceed $30 \%$ in either group.

Table 1. Basic characteristics and inflammatory markers of the study population.

\begin{tabular}{lcc}
\hline Parameter & Controls $\mathbf{( n = 1 6 )}$ & CD $(\mathbf{n}=\mathbf{2 6})$ \\
\hline Gender $($ female $/$ male) & $7 / 9$ & $12 / 14$ \\
Age $($ years) & $15(14-17)$ & $15(13-16)^{\#}$ \\
BMI $\left(\mathrm{kg} . \mathrm{m}^{-2}\right)$ & $17.9(16.2-20.1)$ & $17.8(15.1-20.6)$ \\
$F C(\mu \mathrm{g} / \mathrm{g})$ & $100(100-101)$ & $1638(730-1800)^{* * *}$ \\
CRP $(\mathrm{mg} / \mathrm{l})$ & $1(1-1)$ & $15(5-45)^{* * *}$ \\
$\operatorname{ESR} 1 \mathrm{~h}(\mathrm{~mm})$ & $7(3-9)$ & $30(24-48)^{* * *}$ \\
$\operatorname{ESR} 2 \mathrm{~h}(\mathrm{~mm})$ & $12(9-16)$ & $68(51-100)^{* * *}$ \\
\hline
\end{tabular}

Values are presented as mean $\left(25^{\text {th }}-75^{\text {th }}\right.$ percentile) unless otherwise stated. Absolute patient numbers for given categories are presented. $* * *$ - Mann-Whitney test, $\mathrm{p}<0.001,{ }^{*}$ - ge at diagnosis of CD, CRP - C-reactive protein, ESR - erythrocyte sedimentation rate, $\mathrm{CD}-$ Crohn's disease, BMI - body mass index; [weight $(\mathrm{kg}) /\left(\right.$ height $\left.\left(\mathrm{m}^{2}\right)\right], \mathrm{FC}-$ fecal calprotectin. 
Table 2. Demographics of Crohn's disease (CD) patients enrolled per Paris classification and PCDAI scores.

\begin{tabular}{|c|c|}
\hline Age at diagnosis & \\
\hline A1a: $<10$ years of age & $3.8 \%(1 / 26)$ \\
\hline A1b: 10 to $<17$ years & $69.2 \%(18 / 26)$ \\
\hline A2: 17 to $<40$ years & $27 \%(7 / 26)$ \\
\hline \multicolumn{2}{|l|}{ Disease activity at onset (PCDAI) } \\
\hline Quiescent $<10$ & $3.8 \%(1 / 26)$ \\
\hline Mild to moderate $11-30$ & $42.3 \%(11 / 26)$ \\
\hline Severe $>31$ & $53.9 \%(14 / 26)$ \\
\hline \multicolumn{2}{|l|}{ Disease location } \\
\hline L1: terminal ileum/ileocecal & $19.2 \%(5 / 26)$ \\
\hline $\mathrm{L} 1+\mathrm{L} 4 \mathrm{a}$ & $7.7 \%(2 / 26)$ \\
\hline $\mathrm{L} 1+\mathrm{L} 4 \mathrm{~b}$ & $3.8 \%(1 / 26)$ \\
\hline $\mathrm{L} 1+\mathrm{L} 4 \mathrm{ab}$ & $7.7 \%(2 / 26)$ \\
\hline L2: colonic & $23.1 \%(6 / 26)$ \\
\hline $\mathrm{L} 2+\mathrm{L} 4 \mathrm{a}$ & $7.7 \%(2 / 26)$ \\
\hline $\mathrm{L} 2+\mathrm{L} 4 \mathrm{~b}$ & $7.7 \%(2 / 26)$ \\
\hline $\mathrm{L} 2+\mathrm{L} 4 \mathrm{a} / \mathrm{b}$ & $7.7 \%(2 / 26)$ \\
\hline L3: ileocolonic & $57.7 \%(15 / 26)$ \\
\hline $\mathrm{L} 3+\mathrm{L} 4 \mathrm{a}$ & $38.5 \%(10 / 26)$ \\
\hline $\mathrm{L} 3+\mathrm{L} 4 \mathrm{~b}$ & $15.4 \%(4 / 26)$ \\
\hline $\mathrm{L} 3+\mathrm{L} 4 \mathrm{ab}$ & $3.8 \%(1 / 26)$ \\
\hline \multicolumn{2}{|l|}{ L4: isolated upper tract disease } \\
\hline All upper digestive involvement & $88.5 \%(23 / 26)$ \\
\hline L4a & $61.6 \%(16 / 26)$ \\
\hline $\mathrm{L} 4 \mathrm{~b}$ & $26.9 \%(7 / 26)$ \\
\hline \multicolumn{2}{|l|}{ Disease behavior } \\
\hline B1 inflammatory (non-stricturing, non-penetrating) & $65.4 \%(17 / 26)$ \\
\hline B2 stricturing & $3.8 \%(1 / 26)$ \\
\hline B3 penetrating & $23.1 \%(6 / 26)$ \\
\hline B2/B3 stricturing \& penetrating & $7.7 \%(2 / 26)$ \\
\hline Positive ANCA & $57.7 \%(15 / 26)$ \\
\hline Positive ASCA & $46.2 \%(12 / 26)$ \\
\hline Perianal disease (p) & $23.1 \%(6 / 26)$ \\
\hline Growth delay (G1) & $3.8 \%(1 / 26)$ \\
\hline
\end{tabular}

As defined by Levine et al. (2011). Absolute patient numbers for given categories are presented, values also represent their corresponding percentage of the overall category. ASCA - anti-Saccharomyces cerevisiae antibodies, PCDAI - Pediatric Crohn 's disease activity index, L4a - proximal upper involvement of the angle of Treitz, L4b - distal upper impairment of the angle of Treitz and proximal to the third distal of the ileum.

\section{Diagnostic work-up}

The Paris classification

Table 2 indicates the distribution of CD patients regarding the Paris classification and PCDAI. No patients within the groups had a history of bowel surgery.

\section{Plasma FA profiles}

Significant differences in the FA profiles are displayed in Tables S1 and S2 in the Supplementary Materials. The profile of three major plasma lipid classes was analysed: phospholipids (PLs), triacylglycerols 
(TAGs), and cholesteryl esters (CEs), as detailed in Table S1. Compared with HCs, for PLs and TAGs, we observed higher proportions of n-3 LC PUFAs in CD patients (both $\mathrm{p}<0.001$ ), which was caused by higher contents of DHA (22:6n-3), EPA (20:5n-3) and plasma 22:5n-3 FAs.

Table 3. Dietary intake of fat in pediatric Crohn's disease (CD) patients and controls.

\begin{tabular}{|c|c|c|}
\hline Variable & $C D(n=26)$ & Controls $(n=16)$ \\
\hline \multicolumn{3}{|c|}{$\begin{array}{c}\text { Total energy/per kg of } \\
\text { body weight }\end{array}$} \\
\hline (kcal) & $2037(160.1) / 41.2(2.9)$ & $1892.5(173.5) / 38.7(2.4)$ \\
\hline$(\mathrm{kJ})$ & $8351.7(656.4) / 170.6(11.9)$ & $7920.6(726.6) / 161.5(10.4)$ \\
\hline Total fat (g) & $61.8(18.8)$ & $58.5(16.6)$ \\
\hline$(\mathrm{g} / 1000 \mathrm{kcal})$ & $30.3(2.4)$ & $30.9(2.5)$ \\
\hline$(E n \%)$ & $27.3(2.0)$ & $28.8(2.0)$ \\
\hline Total SFA (g) & $25.1(9.6)$ & $21.1(8.9)$ \\
\hline$(\mathrm{g} / 1000 \mathrm{kcal})$ & $11.3(3.1)$ & $12.4(3.4)$ \\
\hline$(E n \%)$ & $11.5(4.0)$ & $9.9(3.6)$ \\
\hline Total MUFA (g) & $13.1(7.4)$ & $14.8(8.1)$ \\
\hline$(\mathrm{g} / 1000 \mathrm{kcal})$ & $6.4(3.9)$ & $8.8(4.2)$ \\
\hline$(E n \%)$ & $5.8(2.1)$ & $7.1(2.8)$ \\
\hline Total PUFA (g) & $6.7(1.9)$ & $5.1(1.6)$ \\
\hline$(\mathrm{g} / 1000 \mathrm{kcal})$ & $3.3(1.6)$ & $3.1(1.5)$ \\
\hline$(E n \%)$ & $2.1(1.0)$ & $2.4(0.8)$ \\
\hline Total n-3 $(g)$ & $0.5(0.3)$ & $0.3(0.2)$ \\
\hline Total n-6 (g) & $1.7(1.1)$ & $1.4(1.0)$ \\
\hline
\end{tabular}

All differences between groups do not reach statistical significance. Absolute patient numbers for given categories are presented. Observed variables are expressed as the mean (standard error) of average daily intake. $P$ values were calculated by Mann-Whitney $U$ test. CD - Crohn's disease patients, En \% - as percentage of total caloric intake, SFA - Saturated Fatty Acids, MUFA Monounsaturated Fatty Acids, PUFA - Polyunsaturated Fatty Acids, NS - not significant differences ( $p>0.05)$ vs. healthy controls.

Individual FAs of the PUFA n-6 family exhibited a more complicated pattern of changes. In plasma PLs, a higher abundance of arachidonic acid (AA, 20:4n-6) prevailed with a lower content of linoleic acid (LA, 18:2n-6) in the CD group. Among TAGs, the content of AA was increased in the CD group $(p<0.01)$ but did not affect the respective sum. The content of LA in the plasma CEs of CD children was substantially lower $(p<0.01)$ without changes in the sum of n-6 PUFAs, as the content of AA tended to increase in plasma CE. The changes in the content of both families of PUFAs resulted in a lower ratio of $n-6$ PUFAs/n-3 PUFAs in the CD group in PLs $(\mathrm{p}<0.001)$ and TAGs $(\mathrm{p}<0.01)$.

Major Fas (MUFAs) exhibited only moderate changes between the $\mathrm{CD}$ and $\mathrm{HC}$ groups. Oleic acid $(18: 1 n-9)$ was only slightly decreased in plasma PLs in the CD group $(p<0.05)$. In PLs and CEs, the content of cis-vaccenic acid $(18: 1 n-7)$ was higher in the CD group (all $\mathrm{p}<0.05$ ).

The concordant decrease in the PL content of major saturated FAs and palmitic and stearic acids brought about a profound decrease in the saturated FA (SFA) ratio in the $\mathrm{CD}$ group $(\mathrm{p}<0.001)$. For TAGs and CEs, the sum of SFAs did not change.

\section{Plasma FA profile, disease activity and inflammatory markers}

Correlations between FAs, markers of inflammation and disease activity

The correlation coefficients between inflammatory and clinical parameters and the FAs are entirely outlined in Table S2. We found a positive 
association between the content of MUFAs in plasma PLs and the disease activity index $(\mathrm{p}<0.01)$ and negative correlations $(p<0.05)$ between the content of several $n-6$ PUFAs and DHA in the plasma TAG fraction.

\section{Discussion}

Herein, this is the first published report on the abnormalities of plasma FAs in a unique CD cohort of newly diagnosed and therapy-naïve pediatric patients with $\mathrm{CD}$. We have shown that the FA profiles in pediatric CD patients compared to HCs significantly differed. We observed that PUFA metabolism, mainly linked to higher contents of n-3 and n-6 LC PUFAs in PLs and a lower ratio of $n-6 / n-3$ PUFAs in TAGs and PLs, was significantly altered even in new-onset untreated CD. Furthermore, the content of major FAs in PLs significantly correlated with disease activity. Although the pathophysiological relationship is not clear, these data may provide new options for research on pathological processes responsible for the impaired profiles in the early stage of CD.

Many records concerning the effects of PUFAs in pediatric CD have indicated mixed conclusions (Levy et al. 2000, Trebble et al. 2003, Socha et al. 2005, Usami et al. 2003). In this context, ignoring potential confounding factors, we commend the authors of the 3 aforementioned studies for identifying the metabolism of PUFAs in children with IBDs that may, at least to some extent, be compared to ours. Our reference group exhibited lower values of n-3 LC PUFAs than the reported German population (Decsi et al. 1994) and Swedish data (Steel et al. 2006). Our conclusions are closer to values reported by Grogan et al. (2012) for whole plasma. Conversely, the content of n-6 LC PUFAs in our HCs was considerably higher than previously reported (Grogan et al. 2012), mainly due to the increased proportion of LA (18:2n-6).

As previously reported (Trebble et al. 2003), dietary intake in children with IBD was comparable to HC. Another study explored adults with $\mathrm{CD}$ and those without $\mathrm{CD}$; the $\mathrm{CD}$ group had altered profiles and higher total energy intake, but the values of the fat intake and PUFAs did not reach statistical significance (Scoville et al. 2019). Our analyses share a number of similarities with Scoville et al.'s findings (Scoville et al. 2019). Thus, we cannot very likely attribute the observed changes to alterations in dietary intake; moreover, samples of untreated patients were taken while fasting, making it unlikely that these relationships are driving the profile differences between the two groups. Additionally, the mean BMI was similar in both groups, and HCs had no signs of digestive problems resulting in lower n-3 LC PUFA absorption.

Higher contents of n-3 LC PUFAs, ALA and DHA and decreased contents of n-6 PUFAs were described in adults (Esteve-Comas et al. 1992), even in inactive forms (Esteve-Comas et al. 1993). Low levels of n-6 PUFAs with increased levels of ALA were reported in children (Socha et al. 2005). These results are not consistent with ours obtained in this study. The contrasts are probably related to patient selection bias (previous studies were limited by the lack of untreated subjects). A possible explanation for our findings is that less efficient metabolization/utilization of n-3 FAs into antiinflammatory resolvins, maresins and protectins, which are synthesized from DHA and EPA (Serhan et al. 2014), diverts PUFA metabolism towards the $n-6$ biosynthetic pathways that are involved in producing and modifying pro-inflammatory mediators, supporting the concept of enhanced PUFA biosynthesis. We also observed a high content of ARA in plasma PLs, which is usually linked with high ARA dietary intake as a consequence of increased consumption of animal fat, one factor known for increasing the prevalence of CD (Costea et al. 2014), probably due to the provision of substrates for proinflammatory eicosanoids. Our result of an aberrant profile in PL also coincided with that of Geerling et al. (1999). In fact, higher ARA/LA levels and reductions in oleic acid were observed in inflamed colonic mucosa and fecal samples derived from $\mathrm{CD}$ patients, consistent with the fact that the plasma patterns reflect FAs at tissue sites of inflammation (Fernandéz-Banares et al. 1997, Jansson et al. 2009). Several studies have supported biochemical interactions between FAs, FA-derived mediator production and immune reactions (Serhan et al. 2009, Yaqoob et al. 2007). PUFAs correlated with proinflammatory cytokines and disease activity, as reported previously (Scoville et al. 2019). It is quite plausible that the influence of FAs via ARA derivatives might be of relevance in the inflammatory response through different processes that downregulate inflammatory changes and immune modulations at an early stage of the disease.

In the current study, negative correlations of n-6 LC PUFAs and EPA in TAGs with disease activity were in concordance with a higher content of these FAs in $\mathrm{CD}$ patients versus HCs and with the higher activity of the disease demanding more substrate (ARA and EPA, 
respectively) for the production of mediators. Scoville et al. presented an inverse correlation with LA and n-6 LC PUFAs (Scoville et al. 2019) in CD, but they observed a positive correlation of EPA with disease activity. Of note, major MUFAs exhibited only moderate changes between the studied groups. We demonstrated that the content of oleic acid (18:1n-9) and the sum of MUFAs in PLs positively correlated with disease activity, which contradicted the report of Perreault et al. (2014). They reported only weak associations between oleic acid and inflammatory markers in young adults, probably due to the absence of inflammation in the population of healthy young subjects. Our data might be relevant to the underlying mechanisms in the context of altered metabolization/utilization.

To relate our findings to objective inflammatory markers in active CD (Daniluk et al. 2019), we found that the profiles correlated significantly with the inflammatory state in the 2 studied groups we enrolled. However, not all FAs from the same classes were associated with inflammatory markers in active CD. Briefly, correlations of FAs with inflammatory markers were proven for some PUFAs for pooled groups (data not presented), but our results document a relatively weak relationship within the CD group. However, the findings supported by Trebble et al. (2003) could be explained by considerably larger differences obtained between the $\mathrm{HC}$ and $\mathrm{CD}$ groups than within the $\mathrm{CD}$ group. These findings imply that individual FAs may have distinct influences on the development of $\mathrm{CD}$.

Clear strengths and innovative aspects of this study are the inclusion of new-onset and therapy-naïve patients with $\mathrm{CD}$, the prospective design and accurate description of the participants. We focused on untreated CD children to increase the homogeneity of the study population, reducing the risk of biased estimates and the possible confounding influences on the changes in the early decline of FAs other than disease-specific activity. Specific data on dietary records in the diet of the subjects were available; thus, the likely differences in the diet between patients and HCs were of lesser impact. Thus, the observed differences were unrelated to ongoing medication, diet and sampling and reflected the state of active untreated disease. This study had limitations. We also cannot comment on whether there were differences between different disease locations regarding the heterogeneous disease characteristics because various disease subgroups had smaller numbers of participants. Another weakness may be the lack of data on histopathology in HCs, but FC is a surrogate marker of intestinal inflammation (Daniluk et al. 2019). Using a self-report method to assess dietary intake may reduce the potential validity of our data due to the risk of overor under-reporting as well as person-specific sources of bias; nevertheless, these techniques were used previously (Jackson et al. 2008). Although the study determined an unequivocal association, we could not prove casualty, but it is a very good indicator of the disease; therefore, our data analysis must be interpreted carefully. Nevertheless, if a significant association was found, it is important to make it clear that it was from a hypothesisgenerating study; consequently, larger prospective confirmatory studies are required to clarify the strength of any association.

In conclusion, our findings implicate deteriorated utilization/metabolization of PUFAs in CD, even in new-onset treatment-naïve children. We observed significant disturbances in the FA profile in newly diagnosed untreated $\mathrm{CD}$ patients distinct from HCs, notably LC PUFAs. The content of major FAs in PLs strongly correlated with disease activity and the inflammatory response. Our data suggest that additional assessments of the unbalanced $n-6 / n-3$ ratio may provide clues regarding the underlying pathogenesis, in particular CD. Finally, the specific mechanisms by which abnormalities in FA profiles, most notably PUFAs, affect the early stage and progression of $\mathrm{CD}$ are still unknown. Nonetheless, the current findings highlight areas for larger prospective studies for this purpose.

\section{Conflict of Interest}

There is no conflict of interest.

\section{Acknowledgements}

This study was supported by research grants PROGRES Q39, PROGRES Q25 and RVO-VFN64165.

\section{References}

CHILTON FH, DUTTA R, REYNOLDS LM, SERGEANT S, MATHIAS RA, SEEDS MC: Precision nutrition and omega-3 polyunsaturated fatty acids: A case for personalized supplementation approaches for the prevention and management of human diseases. Nutrients 9: 1165, 2017. https://doi.org/10.3390/nu9111165 
COSTEA I, MACK DR, LEMAITRE RN, ISRAEL D, MARCIL V, AHMAD A, AMRE DK: Interactions between the dietary polyunsaturated fatty acid ratio and genetic factors determine susceptibility to paediatric Crohn's disease. Gastroenterology 146: 929-931, 2014. https://doi.org/10.1053/j.gastro.2013.12.034

DANILUK U, DANILUK J, KRASNODEBSKA M, LOTOWSKA JM, SOBANIEC-LOTOWSKA ME, LEBENSZTEJN DM: The combination of fecal calprotectin with ESR, CRP and albumin discriminates more accurately children with Crohn's disease. Adv Med Sci 64: 9-14, 2019. https://doi.org/10.1016/j.advms.2018.08.001

DECSI T, KOLETZKO B: Fatty acid composition of plasma lipid classes in healthy subjects from birth to young adulthood. Eur J Pediatr 153: 520-525, 1994. https://doi.org/10.1007/s004310050184

ESTEVE-COMAS M, RAMÍREZ M, FERNÁNDEZ-BAÑARES F, ABAD-LACRUZ A, GIL A, CABRÉ E, GONZÁLEZ-HUIX F, MORENO J, HUMBERT P, GUILERA M: Plasma polyunsaturated fatty acid pattern in active inflammatory bowel disease. Gut 33: 1365-1369, 1992. https://doi.org/10.1136/gut.33.10.1365

ESTEVE-COMAS M, NUÑEZ MC, FERNÁNDEZ-BAÑARES F, ABAD-LACRUZ A, GIL A, CABRÉ E, GONZÁLEZ-HUIX F, BERTRÁN X, GASSULL MA: Abnormal plasma polyunsaturated fatty acid pattern in non-active inflammatory bowel disease. Gut 34: 1370-1373, 1993. https://doi.org/10.1136/gut.34.10.1370

FAEGAN BG, SANDBORN WJ, MITTMANN U, BAR-MEIR S, D'HAENS G, BRADETTE M, COHEN A, DALLAIRE C, PONICH TP, MCDONALD JWD, HÉBUTERNE X, PARÉ P, KLVANA P, NIV Y, ARDIZZONE S, ALEXEEVA O, ROSTOM A, KIUDELIS G, SPLEISS J, GILGEN D, ET AL.: Omega-3 free fatty acids for the maintenance of remission in Crohn disease: the EPIC randomized controlled trial. JAMA 299: 1690-1697, 2008. https://doi.org/10.1001/jama.299.14.1690

FERNÁNDEZ-BAÑARES F, ESTEVE-COMAS M, MANÉ J, NAVARRO E, BERTRÁN X, CABRÉ E, BARTOLÍ R, BOIX J, PASTOR C, GASSULL MA: Changes in mucosal fatty acid profile in inflammatory bowel disease and experimental inflammation. Clin Nutr 16: 177-183, 1997. https://doi.org/10.1016/S0261-5614(97)80003-9

FOLCH J, LEES M, SLOAN-STANLEY GH: A simple method for the isolation and purification of total lipids from animal tissue. J Biol Chem 226: 497-509, 1957. https://doi.org/10.1016/S0021-9258(18)64849-5

GEERLING BJ, V HOUWELINGEN AC, BADART-SMOOK A, STOCKBRUGEGER RW, BRUMMER RJ: The relation between antioxidant status and alterations in fatty acid profile with Crohn disease and controls. Scand J Gastroenterol 34: 1108-1116, 1999. https://doi.org/10.1080/003655299750024913

GONZÁLEZ-GIL EM, SANTABÁRBARA J, SIANI A, AHRENS W, SIOEN I, EIBEN G, GÜNTHER K, IACOVIELLO L, MOLNAR D, RISÉ P, RUSSO P, TORNARITIS M, VEIDEBAUM T, GALLI C, MORENO LA: Whole-blood fatty acids and inflammation in European children: the IDEFICS Study. Eur J Clin Nutr 70: 819-823, 2016. https://doi.org/10.1038/ejen.2015.219

GROGAN JL, CASSON DH, TERRY A, BURDGE GC, EL-MATARY W, MARK DALZELL A: Enteral feeding therapy for newly diagnosed pediatric Crohn's disease: a double blind randomized controlled trial with two years follow-up. Inflamm Bowel Dis 18: 246-253, 2012. https://doi.org/10.1002/ibd.21690

HARRIS C, DEMMELMAIR H, VON BERG A, LEHMANN I, FLEXEDER C, KOLETZKO B, HEINRICH J, STANDL M: Associations between fatty acids and low-grade inflammation in children from the LISAplus birth cohort study. Eur J Clin Nutr 71: 1303-1311, 2017. https://doi.org/10.1038/ejen.2017.73

HOU JK, ABRAHAM B, EL-SERAG H: Dietary intake and risk of developing inflammatory bowel disease: A systematic review of the literature. Am J Gastroenterol 106: 563-573, 2011. https://doi.org/10.1038/ajg.2011.44

HYAMS J, MARKOWITZ J, OTLEY A, ROSH J, MACK D, BOUSVAROS A, KUGATHASAN S, PFEFFERKORN M, TOLIA V, EVANS J, TREEM W, WYLLIE R, ROTHBAUM R, DEL ROSARIO J, KATZ A, MEZOFF A, OLIVA-HEMKER M, LERER T, GRIFFITHS A, PEDIATRIC INFLAMMATORY BOWEL DISEASE COLLABORATIVE RESEARCH GROUP: Evaluation of the pediatric Crohn disease activity index: a prospective multicenter experience. J Pediatr Gastroenterol Nutr 41: 416-421, 2005. https://doi.org/10.1097/01.mpg.0000183350.46795.42

INNES JK, CALDER PC: Omega-6 fatty acids and inflammation. Prostaglandins Leukot Essent Fatty Acids 132: 41-48, 2018. https://doi.org/10.1016/j.plefa.2018.03.004

JACKSON KA, BYRNE NM, MAGAREY AM, HILLS AP: Minimizing random error in dietary intakes assessed by 24-h recall, in overweight and obese adults. Eur J Clin Nutr 62: 537-543, 2008. https://doi.org/10.1038/sj.ejcn. 1602740 
JANSSON J, WILLING B, LUCIO M, FEKETE A, DICKSVED J, HALFVARSON J, TYSK C, SCHMITT-KOPPLIN P: Metabolomics reveals metabolic biomarkers of Crohn's disease. PLoS One 4: e6386, 2009. https://doi.org/10.1371/journal.pone.0006386

LEVINE A, KOLETZKO S, TURNER D, ESCHER JC, CUCCHIARA S, DE RIDDER L, KOLHO K-L, VERES G, RUSSELL RK, PAERREGAARD A, BUDERUS S, GREER M-LC, DIAS JA, VEEREMAN-WAUTERS G, LIONETTI P, SLADEK M, DE CARPI JM, STAIANO A, RUEMMELE FM, WILSON DC, ET AL.: ESPGHAN revised Porto criteria for the diagnosis of inflammatory bowel disease in children and adolescents. J Pediatr Gastroenterol Nutr 58: 795-806, 2014. https://doi.org/10.1097/MPG.0000000000000239

LEVINE A, GRIFFITHS A, MARKOWITZ J, WILSON DC, TURNER D, RUSSELL RK, FELL J, RUEMMELE FM, WALTERS T, SHERLOCK M, DUBINSKY D, HYAMS JS: Pediatric modification of the Montreal classification for inflammatory bowel disease: the Paris classification. Inflamm Bowel Dis 17: 1314-1321, 2011. https://doi.org/10.1002/ibd.21493

LEVY E, RIZWAN Y, THIBAULT L, LEPAGE G, BRUNET S, BOUTHILLIER L, SEIDMAN E: Altered lipid profile, lipoprotein composition, and oxidant and antioxidant status in pediatric Crohn disease. Am J Clin Nutr 71: 807-815, 2000. https://doi.org/10.1093/ajcn/71.3.807

LEWIS JD, ABREU MT: Diet as a trigger or therapy for inflammatory bowel diseases. Gastroenterology 152: 398-414, 2017. https://doi.org/10.1053/j.gastro.2016.10.019

MARION-LETELliER R, SAVOYE G, BECK PL, PANACCIONE R, GHOS S: Polyunsaturated fatty acids in inflammatory bowel diseases: a reappraisal of effects and therapeutic approaches. Inflamm Bowel Dis 19: 650-661, 2013. https://doi.org/10.1097/MIB.0b013e3182810122

MARTON LT, GOULART RA, CARVALHO ACA, BARBALHO SM: Omega fatty acids and inflammatory bowel diseases: An overview. Int J Mol Sci 20: 4851, 2019. https://doi.org/10.3390/ijms20194851

NAGATAKE T, KUNISAWA J: Emerging roles of metabolites of $\omega 3$ and $\omega 6$ essential fatty acids in the control of intestinal inflammation. Int Immunol 31: 569-577, 2019. https://doi.org/10.1093/intimm/dxy086

NIELSEN AA, JORGENSEN LGM, NIELSEN JN, EIVINDSON M, GRØNBAEK H, VIND I, HOUGAARD DM, SKOGSTRAND K, JENSEN S, MUNKHOLM P, BRANDSLUND I, HEY H: Omega-3 fatty acids inhibit an increase of proinflamatory cytokines in patients with active Crohn' disease compared with omega- 6 fatty acids. Aliment Pharmacol Ther 22: 1121-1128, 2005. https://doi.org/10.1111/j.1365-2036.2005.02698.x

PERREAULT M, ROKE K, BADAWI A, NIELSEN DE, ABDELMAGID SA, EL-SOHEMY A, MA DWL, MUTCH DM: Plasma levels of 14:0, 16:0, 16:1n-7, and 20:3n-6 are positively associated, but 18:0 and 18:2n-6 are inversely associated with markers of inflammation in young healthy adults. Lipids 49: 255-263, 2014. https://doi.org/10.1007/s11745-013-3874-3

SAIKA A, NAGATAKE T, KUNISAWA J: Host- and microbe-dependent dietary lipid metabolism in the control of allergy, inflammation, and immunity. Front Nutr 6: 36, 2019: https://doi.org/10.3389/fnut.2019.00036

SCOVILLE EA, ALLAMAN MM, ADAMS DW, MOTLEY AK, PEYTON SC, FERGUSON SL, HORST SN, WILLIAMS CS, BEAULIEU DB, SCHWARTZ A, WILSON KT, COBURN LA: Serum polyunsaturated fatty acids correlate with serum cytokines and clinical disease activity in Crohn's disease. Sci Rep 9: 2882, 2019. https://doi.org/10.1038/s41598-019-39232-z

SERHAN CN: Novel pro-resolving lipid mediators in inflammation are leads for resolution physiology. Nature 510: 92-101, 2014. https://doi.org/10.1038/nature13479

SERHAN CN: Systems approach to inflammation resolution: identification of novel anti-inflammatory and pro-resolving mediators. J Thromb Haemost (Suppl 1): 44-48, 2009. https://doi.org/10.1111/j.1538-7836.2009.03396.x

SOCHA P, RYZKO J, KOLETZKO B, CELINSKA-CEDRO D, WOYNAROWSKI M, CZUBKOWSKI P, SOCHA J: Essential fatty acid depletion in children with inflammatory bowel disease. Scand J Gastroenterol 40: 573-577, 2005. https://doi.org/10.1080/00365520510012136

STEEL DM, RYD W, ASCHER H, STRNADVIK B: Abnormal fatty acid pattern in intestinal mucosa of children with coeliac disease is not reflected in serum phospholipids. J Pediatr Gastroenterol Nutr 43: 318-323, 2006. https://doi.org/10.1097/01.mpg.0000228107.98863.45 
SÝKORA J, POMAHAČOVÁ R, KRESLOVÁ M, CVALÍNOVÁ D, ŠTYCH P, SCHWARZ J: Current global trends in the incidence of pediatric-onset inflammatory bowel disease. World J Gastroenterol 24: 2741-2763, 2018. https://doi.org/10.3748/wjg.v24.i25.2741

TREBBLE TM, WOOTTON SA, MAY A, ERLEWYN-LAJEUNESSE MDS, CHAKRABORTY A, MULLEE MA, STROUD MA, BEATTIE RM: Essential fatty acid status in pediatric Crohn's disease: relationship with disease activity and nutritional status. Aliment Pharmacol Ther 18: 433-442, 2003. https://doi.org/10.1046/j.1365-2036.2003.01707.x

USAMI M, KOMURASAKI T, HANADA A, KINOSHITA K, OHATA A: Effect of gamma-ALA or docosahexaenoic acid on tight junction permeability in intestinal monolayer cells and their mechanism by protein kinase $\mathrm{C}$ activation and/or eicosanoid formation. Nutrition 19: 150-156, 2003. https://doi.org/10.1016/S0899-9007(02)00927-9

VECKA M, TVRZICKÁ E, STANKOVÁ B, ŽÁK A: Effect of column and software on gas chromatographic determination of fatty acids. J Chromatogr B Analyt Technol Biomed Life Sci 770: 91-99, 2002. https://doi.org/10.1016/S1570-0232(01)00630-4

YAQOOB P, CALDER CP: Fatty acids and immune function: new insight into mechanisms. Br J Nutr 98 (Suppl 1): S41-S45, 2007. https://doi.org/10.1017/S0007114507832995 
Supplementary Table 1. Fatty acid composition of lipid classes in plasma in Crohn's disease (CD) as compared with controls.

\begin{tabular}{|c|c|c|c|c|c|c|}
\hline \multirow{2}{*}{ Fatty acid ${ }^{a}$} & \multicolumn{2}{|c|}{ Phospholipids } & \multicolumn{2}{|c|}{ Triacylglycerols } & \multicolumn{2}{|c|}{ Cholesteryl esters } \\
\hline & Controls & CD & Controls & CD & Controls & CD \\
\hline 14:0 & $0.28[0.24-0.31]$ & $\begin{array}{c}0.17[0.11- \\
0.22]^{* * *}\end{array}$ & $2.1[1.53-2.42]$ & $\begin{array}{c}1.02[0.72- \\
1.47]^{* *}\end{array}$ & $0.58[0.51-0.70]$ & $0.42[0.36-0.57$ \\
\hline 16:0 & $\begin{array}{c}1.56 \text { [30.69- } \\
33.03]\end{array}$ & $\begin{array}{c}29.54[27.06- \\
30.35]^{* *} \\
\end{array}$ & $\begin{array}{c}28.18 \text { [26.95- } \\
29.11] \\
\end{array}$ & $\begin{array}{c}25.71 \text { [24.11- } \\
27.50]\end{array}$ & $\begin{array}{r}11.41[ \\
11 .\end{array}$ & $\begin{array}{c}12.31[10.92- \\
13.60]\end{array}$ \\
\hline $16: 1 n-9$ & $0.11[0.11-0.14]$ & $0.12[0.10-0.13]$ & $0.79[0.75-0.95]$ & $\begin{array}{c}0.61[0.51- \\
0.64]^{* * *}\end{array}$ & $0.53[0.41-0.55]$ & $0.47[0.40-0.51]$ \\
\hline $16: 1 n-7$ & $0.47[0.43-0.64]$ & $0.46[0.40-0.60]$ & $3.25[3.00-3.48]$ & $\begin{array}{l}2.88[2.24- \\
3.22]^{*}\end{array}$ & $2.36[2.10-2.92]$ & $2.78[2.04-3.31]$ \\
\hline 18:0 & $83-$ & 15. & $3.08[2.74-3.52]$ & $3.34[2.64-4.15]$ & $0.88[0.72-1.24]$ & $0.74[0.62-0.83]$ \\
\hline $18: 1 n-9$ & $\begin{array}{c}12.12 \text { [11.6- } \\
13.51]\end{array}$ & $\begin{array}{c}11.17 \text { [10.47- } \\
11.94]^{*}\end{array}$ & $\begin{array}{r}41.31 \\
43 .\end{array}$ & $\begin{array}{r}42.86 \\
44 .\end{array}$ & $\begin{array}{r}21.08 \\
21 \\
\end{array}$ & $\begin{array}{r}22.82 \text { | } 26 . \\
\end{array}$ \\
\hline $18: 1 n-7$ & 1.51 [1.31-1.75] & $\begin{array}{l}1.84[1.70- \\
2.03]^{*}\end{array}$ & $2.26[2.09-2.55]$ & $2.56[2.33-2.73]$ & $0.83[0.78-0.92]$ & $\begin{array}{c}1.51[1 \\
1.84]^{*}\end{array}$ \\
\hline $18: 2 n-6$ & $\begin{array}{r}24.00 \\
24 \\
\end{array}$ & $\begin{array}{r}21.18 \\
22 . \\
\end{array}$ & $\begin{array}{c}15.48 \text { [13.96- } \\
16.99] \\
\end{array}$ & $\begin{array}{c}16.06[13.42- \\
18.01] \\
\end{array}$ & $\begin{array}{r}55.77 \\
56 \\
\end{array}$ & $\begin{array}{r}51.41[4 \\
54.13 \\
\end{array}$ \\
\hline $18: 3 n-6$ & $.09[0.06-0.10]$ & $0.11[0.08-0.17]$ & $26[0.20-0.31]$ & $0.23[0.16-0.35]$ & 0.89 [0.43-0.97] & $0.52[0.3$ \\
\hline $18: 3 n-3$ & $0.19[0.12-0.25]$ & $0.20[0.15-0.28]$ & 2] & 0.69 [0.50-0.89] & $0.53[0.4$ & $0.45[0$. \\
\hline $20: 2 n-6$ & $1.11[0.82-1.26]$ & $\begin{array}{c}0.34[0.27- \\
0.45]^{* * *} \\
\end{array}$ & $0.42[0.37-0.50]$ & $\begin{array}{r}0.15 \\
0.21 \\
\end{array}$ & $0.09[0.07$ & $0.06[0-0.11]$ \\
\hline $20: 3 n-6$ & $3.09[2.88-3.36]$ & $3.18[2$. & $0.29[0.26-$ & $0.26[0$. & 0.62 & $\begin{array}{c}0.79[0.66- \\
1.09]^{* * *}\end{array}$ \\
\hline $20: 4 n-6$ & $8.19[6.82-8.56]$ & $\begin{aligned} 12.19 \\
13.2\end{aligned}$ & $0.49[0.39-0.58]$ & $\begin{array}{c}1.52[0 \\
1.87]^{\prime}\end{array}$ & $3.54[3.02$ & $5.12[3$. \\
\hline $20: 5 n-3$ & $0.25[0.15-0.35]$ & $\begin{array}{r}0.58 \\
0.7\end{array}$ & $0.04[0.03-0.05]$ & $\begin{array}{l}7- \\
*\end{array}$ & $0.13[0.07-0.18]$ & $0.10[0.05-0.27]$ \\
\hline $22: 4 n-6$ & $0.17[0.14-0.19]$ & $\begin{array}{r}0.4 \\
0 .\end{array}$ & $0.04[0.04-0.05]$ & $\begin{aligned} 0.1 & \\
0 . & \end{aligned}$ & $0.01[0.01-0.02]$ & $0.01[0-0.02]$ \\
\hline $22: 5 n-6$ & $0.09[0.07-0.11]$ & $\begin{array}{c}0.32[0.25- \\
0.37]^{* * *}\end{array}$ & $.02[0.01-0.02]$ & $\begin{array}{c}0.12[0.08- \\
0.17]^{* * *} \\
\end{array}$ & $0.01[0-0.01]$ & $0.01[0-0.02]$ \\
\hline $22: 5 n-3$ & $31[0.22-0.36]$ & $\begin{array}{c}0.83[0.73- \\
1.00]^{* * *}\end{array}$ & $.04[0.03-0.04]$ & $\begin{array}{c}0.27[0.21- \\
0.33]^{* * *} \\
\end{array}$ & $0.01[0.01-0.03]$ & $0.01[0-0.04]$ \\
\hline $22: 6 n-3$ & $0.67[0.51-0.72]$ & $\begin{array}{c}2.78[2.47- \\
3.50]^{* * *}\end{array}$ & $0.03[0.02-0.03]$ & $\begin{array}{c}0.34[0.18- \\
0.40]^{* * *}\end{array}$ & $0.06[0.05-0.09]$ & $0.02[0-0.06]$ \\
\hline$\Sigma$ satur & $\begin{array}{c}48.55 \text { [48.05- } \\
49.19]\end{array}$ & $\begin{array}{c}43.43[42.25- \\
44.25]^{* * *}\end{array}$ & 32.75 [31.6- & $\begin{array}{c}30.12[27.95- \\
32.01]\end{array}$ & $13.08[12.26-$ & $\begin{array}{c}13.44[11.86- \\
15.06]\end{array}$ \\
\hline ¿mono & $\begin{array}{c}14.68[13.96- \\
16.29]\end{array}$ & $\begin{array}{c}13.69[12.96- \\
14.61]\end{array}$ & $\begin{array}{c}48.64[46.96- \\
50.56]\end{array}$ & $\begin{array}{c}48.67[46.02- \\
51.51]\end{array}$ & $\begin{array}{c}24.83[23.65- \\
25.65]\end{array}$ & $\begin{array}{c}27.53 \text { [23.97- } \\
30.77]\end{array}$ \\
\hline$\sum n-6$ & $\begin{array}{c}35.92[33.28- \\
36.59]\end{array}$ & $\begin{array}{c}38.42[35.16- \\
39.15]\end{array}$ & $\begin{array}{c}17.15[15.65- \\
18.63]\end{array}$ & $\begin{array}{c}18.66[15.26- \\
21.27] \\
\end{array}$ & $\begin{array}{c}61.17 \text { [60.25- } \\
63.47] \\
\end{array}$ & $\begin{array}{c}56.96[54.28- \\
63.07] \\
\end{array}$ \\
\hline$\sum n-3$ & $1.30[1.23-1.68]$ & $\begin{array}{l}4.46[4.17- \\
5.50]^{* * *}\end{array}$ & $0.96[0.86-1.06]$ & $\begin{array}{c}1.36[1.13- \\
1.80]^{* * *}\end{array}$ & $0.88[0.61-1.05]$ & $0.67[0.44-0.95]$ \\
\hline$\sum n-6 / \sum n-3$ & $\begin{array}{c}25.54 \text { [20.94- } \\
28.52]\end{array}$ & $\begin{array}{c}8.43[6.96- \\
9.61]^{* * *}\end{array}$ & $\begin{array}{c}15.82[14.33- \\
22.38]\end{array}$ & $\begin{array}{c}13.41[10.60- \\
15.10]^{* *}\end{array}$ & $\begin{array}{c}71.48 \text { [56.47- } \\
99.90]\end{array}$ & $\begin{array}{c}94.24 \text { [64.49- } \\
129.6]\end{array}$ \\
\hline
\end{tabular}

$\Sigma$ - sum, values - are expressed as mean $\left(25^{\text {th }}-75^{\text {th }}\right.$ percentile) (mol\%), $t$-test: $* p<0.05, * p<0.01, * * p<0.001$, a/ - shorthand notation of fatty acids - number before colon=number of double bonds; number after $n=$ number of carbon atoms from the methyl end of the chain to the nearest double bond. CD - Crohn's disease. 
Supplementary Table 2. Correlation of selected inflammatory parameters and PCDAl with fatty acid composition of plasma lipid classes.

\begin{tabular}{|c|c|c|c|c|c|c|c|c|c|}
\hline \multirow{2}{*}{ Fatty acid ${ }^{a}$} & \multicolumn{3}{|c|}{ Phospholipids } & \multicolumn{3}{|c|}{ Triacylglycerols } & \multicolumn{3}{|c|}{ Cholesteryl esters } \\
\hline & FC & CRP & PCDAI & FC & CRP & PCDAI & FC & CRP & PCDAI \\
\hline 14:0 & 0.234 & -0.189 & 0.128 & 0.362 & -0.147 & 0.175 & 0.067 & -0.182 & -0.105 \\
\hline 16:0 & 0.115 & -0.118 & 0.429 & $0.438 *$ & -0.383 & -0.002 & 0.008 & 0.135 & 0.071 \\
\hline $16: 1 n-9$ & 0.165 & 0.372 & 0.031 & -0.183 & 0.035 & 0.100 & -0.040 & -0.227 & -0.218 \\
\hline $16: 1 n-7$ & 0.283 & 0.041 & -0.152 & -0.034 & 0.107 & -0.112 & -0.029 & -0.001 & -0.117 \\
\hline 18:0 & -0.001 & 0.108 & 0.226 & 0.124 & 0.122 & 0.318 & 0.005 & 0.016 & -0.030 \\
\hline $18: 1 n-9$ & 0.291 & 0.387 & $0.644^{* *}$ & -0.054 & 0.447 & 0.289 & 0.057 & 0.280 & 0.211 \\
\hline $18: 1 n-7$ & 0.168 & 0.257 & 0.225 & 0.064 & -0.217 & -0.291 & -0.033 & 0.425 & 0.091 \\
\hline $18: 2 n-6$ & 0.067 & -0.094 & -0.118 & -0.322 & -0.189 & -0.418 & -0.075 & -0.369 & -0.278 \\
\hline $18: 3 n-6$ & 0.282 & 0.045 & 0.111 & -0.049 & -0.140 & -0.209 & 0.126 & -0.043 & 0.085 \\
\hline $18: 3 n-3$ & 0.262 & 0.029 & 0.038 & 0.054 & -0.164 & -0.274 & 0.228 & -0.004 & 0.100 \\
\hline $20: 2 n-6$ & 0.157 & -0.225 & 0.174 & -0.161 & -0.003 & 0.070 & -0.357 & -0.341 & -0.210 \\
\hline $20: 3 n-6$ & -0.101 & -0.260 & -0.282 & -0.363 & -0.031 & -0.356 & -0.113 & -0.095 & -0.125 \\
\hline $20: 4 n-6$ & -0.367 & -0.014 & -0.258 & $-0.623^{* *}$ & 0.003 & -0.248 & 0.068 & 0.155 & 0.270 \\
\hline $20: 5 n-3$ & -0.052 & -0.142 & -0.477 & -0.189 & 0.054 & -0.409 & 0.254 & 0.109 & 0.273 \\
\hline $22: 4 n-6$ & 0.119 & -0.027 & -0.029 & -0.364 & 0.072 & -0.346 & -0.321 & -0.408 & -0.358 \\
\hline $22: 5 n-6$ & 0.279 & -0.271 & -0.253 & -0.365 & -0.171 & $-0.644^{* *}$ & -0.273 & -0.353 & -0.323 \\
\hline $22: 5 n-3$ & 0.144 & 0.112 & -0.138 & -0.296 & 0.132 & -0.385 & -0.244 & -0.202 & -0.241 \\
\hline $22: 6 n-3$ & 0.063 & 0.024 & -0.369 & -0.160 & -0.088 & $-0.584 * *$ & -0.198 & -0.173 & -0.115 \\
\hline$\sum$ satur & 0.045 & 0.160 & 0.339 & $0.427 *$ & -0.312 & 0.103 & 0.012 & 0.103 & 0.050 \\
\hline Smono & 0.412 & $0.424 *$ & $0.661^{* *}$ & -0.010 & 0.440 & 0.287 & 0.019 & 0.254 & 0.156 \\
\hline$\Sigma n-6$ & -0.338 & -0.317 & -0.459 & $-0.448^{*}$ & -0.164 & -0.453 & -0.015 & -0.221 & -0.118 \\
\hline$\Sigma n-3$ & 0.062 & 0.056 & -0.378 & -0.229 & -0.128 & $-0.618 * *$ & 0.282 & 0.059 & 0.136 \\
\hline$\Sigma n-6 / \Sigma n-3$ & -0.111 & -0.174 & 0.275 & 0.004 & 0.103 & 0.471 & -0.335 & -0.168 & -0.230 \\
\hline
\end{tabular}

Only Crohn's disease (CD) group. Spearman rank correlation coefficients: * $p<0.05, * * p<0.01, * * * p<0.001 . \Sigma-$ Sum, a/ - shorthand notation of fatty acids- number before colon=number of double bonds; number after $n=$ number of carbon atoms from the methyl end of the chain to the nearest double bond. CRP - C-reactive protein, FC - fecal calprotectin, PCDAl - Paediatric Crohn's Disease Activity Index. 